\title{
Investigation of the reaction of 3-aroylmethylene-indol-2-ones with 2-hydrazinobenzothiazole
}

\author{
RENUKA JAIN*, KANTI SHARMA and DEEPAK KUMAR \\ Department of Chemistry, University of Rajasthan, Jaipur 302 004, India \\ e-mail: profrjain@rediffmail.com
}

MS received 2 February 2012; revised 20 June 2012; accepted 20 July 2012

\begin{abstract}
The reactions of 3-aroylmethylene-indol-2-ones with 2-hydrazinobenzothiazole in different media and solvent were investigated. The impact of substitution on indolyl nitrogen was also studied. The chemical structure of the products was proven on the basis of their spectral (IR, ${ }^{1} \mathrm{H}-\mathrm{NMR},{ }^{13} \mathrm{C}-\mathrm{NMR}$, Mass) and analytical studies.
\end{abstract}

Keywords. 3-Aroylmethylene-indol-2-ones; spiro[indole-pyrazole]; hydrazone; pyridazine; ionic liquid.

\section{Introduction}

Keeping in view a variety of pharmacological activities associated with benzothiazole ${ }^{1-3}$ and pyrazole nuclei, ${ }^{4-6}$ it was perceived that the synergistic effect of heterocyclic moieties in single nucleus might result in the formation of some worthwhile molecules from the biological point of view. Therefore, some novel bioactive compounds incorporating these two moieties have been synthesized. Reaction of indole-2,3-diones ${ }^{7,8}$ with acetophenone gave 3-hydroxy-3-phenacyl-indol-2-ones which on further dehydration with $\mathrm{HCl}$ and $\mathrm{CH}_{3} \mathrm{COOH}$, furnishes 3-aroylmethylene-indol-2-ones (1a-b). These compounds are highly reactive due to the presence of an alkene system flanked by carbonyl group. The nature of substituent on the nitrogen atom plays a significant role in the formation of products. ${ }^{9}$

The reaction of 3-aroylmethylene-indol-2-ones with various compounds viz., hydrazines, ${ }^{10}$ thiosemicarbazide $^{11}$ and hydrazinobenzimidazole ${ }^{12}$ have been previously investigated by us but the reaction with 2hydrazinobenzothiazole has not been studied so far. In the present report, a detailed investigation of the reactions of 3-aroylmethylene-indol-2-ones with 2-hydrazinobenzothiazole in different solvent and medium was undertaken. The effect of substitution on the indolyl nitrogen has also been studied.

*For correspondence

\section{Experimental}

\subsection{Material, methods and instruments}

Melting points were determined in open end capillaries using Gallenkamp melting point apparatus and are uncorrected. The purity of the compounds was checked by thin-layer chromatography (TLC) on silica gel plate using benzene and ethyl acetate (4:1) as eluent and spots were located by iodine vapours. The IR spectra were recorded on an 8400S SHIMADZU IR spectrometer using $\mathrm{KBr}$ pellets and band positions were recorded in wave numbers $\left(\mathrm{cm}^{-1}\right)$. ${ }^{1} \mathrm{H}$ - and ${ }^{13} \mathrm{C}$-NMR spectra were recorded in DMSO$\mathrm{d}_{6} / \mathrm{CDCl}_{3}$ with TMS as an internal reference on a JEOL spectrometer at 300 and $75 \mathrm{MHz}$, respectively. The ionic liquid, [bmim] $\mathrm{PF}_{6}$ was purchased from ACROS ORGANICS. 3-Aroylmethylene-indol-2-ones (1a-b) were prepared according to literature method ${ }^{13}$ and 2hydrazinobenzothiazole (2) by the method of Sharma et al. ${ }^{14}$

\subsection{Synthesis of 3-benzoyl(2-benzothiazolyl hydrazone)methylene-indol- $2(1 \mathrm{H})$ ones $\mathbf{3 a}-\boldsymbol{b}$}

Equimolar quantities of 3-aroylmethylene-indol-2-ones (1a-b) (0.01 mol) and 2-hydrazinobenzothiazole (2) $(0.01 \mathrm{~mol})$ were dissolved in absolute alcohol $(10 \mathrm{~mL})$ and acetic acid $(1 \mathrm{~mL})$ added as a catalyst and reaction mixture was refluxed for $4-5 \mathrm{~h}$. After completion of the reaction as indicated by TLC, the reaction mixture was cooled at room temperature and resultant solid 
was washed with ethanol, dried and recrystallized from ethanol to yield product.

2.2a 3-Benzoyl(2-benzothiazolyl hydrazone)methyleneindol-2(1H)-one (3a): IR (KBr): 3200-3380 (NH), $1670(>\mathrm{C}=\mathrm{O}), 1620(\mathrm{C}=\mathrm{N})$; ${ }^{1} \mathrm{H}-\mathrm{NMR}(\delta) \mathrm{ppm}: 6.18$ $(1 \mathrm{H}, \mathrm{s},=\mathrm{CH}-), 7.14(1 \mathrm{H}, \mathrm{s},-\mathrm{NH}), 6.91-7.85(13 \mathrm{H}, \mathrm{m}$, Ar-H), $10.43\left(1 \mathrm{H}, \mathrm{s},>\mathrm{NH}\right.$ of indole); ${ }^{13} \mathrm{C}-\mathrm{NMR}(\delta)$ ppm: 121.3 (=CH-), 117.5-133.8 (aromatic carbons), $147.5(\mathrm{C}=\mathrm{N}), 189.2(>\mathrm{C}=\mathrm{O}) ; \mathrm{MS}(\mathrm{m} / \mathrm{z}): 396\left(\mathrm{M}^{+}\right)$.

2.2b 3-Benzoyl-1-methyl(2-benzothiazolyl hydrazone) methylene-indol-2(1H)-one (3b): IR (KBr): 3310 $(\mathrm{NH}), 1690(>\mathrm{C}=\mathrm{O}), 1630(\mathrm{C}=\mathrm{N}) ;{ }^{1} \mathrm{H}-\mathrm{NMR}(\delta) \mathrm{ppm}$ : $3.27\left(3 \mathrm{H}, \mathrm{s},-\mathrm{NCH}_{3}\right), 6.23(1 \mathrm{H}, \mathrm{s},=\mathrm{CH}-), 7.36(1 \mathrm{H}, \mathrm{s}$, -NH), 6.82-7.58 (13H, m, Ar-H); ${ }^{13} \mathrm{C}-\mathrm{NMR}(\delta) \mathrm{ppm}$ : $34.8\left(\mathrm{NCH}_{3}\right), 122.1$ (=CH-), 117.9-137.5 (aromatic carbons), $149.2(\mathrm{C}=\mathrm{N}), 189.3(>\mathrm{C}=\mathrm{O})$.

2.3 Preparation of $1^{\prime}$-benzothiazolo-5'-phenyl-2',4'dihydrospiro[indole-3,3'-pyrazol]-2(1H)-ones $4 a-b$

A mixture of 1a-b $(0.01 \mathrm{~mol}), 2 \quad(0.01 \mathrm{~mol})$ and [bmim] $\mathrm{PF}_{6}$, an ionic liquid $(5 \mathrm{~mL})$ was taken in a round bottom flask without catalyst and solution was stirred magnetically for $4-5 \mathrm{~h}$ at $80 \pm 2^{\circ} \mathrm{C}$ under nitrogen atmosphere. After completion of reaction as evidenced by TLC, the reaction mixture was cooled at room temperature and contents were neutralized by $10 \%$ aqueous sodium bicarbonate solution and extracted with ethyl acetate $(3 \times 10 \mathrm{~mL})$. The solvent was removed under reduced pressure. The pasty mass, thus obtained was extracted with diethyl ether $(3 \times 10 \mathrm{~mL})$, dried over anhydrous sodium sulphate, ether distilled off and the obtained crude mixture of products was purified by crystallization with ethanol to yield spiro product $(\mathbf{4 a}-\mathbf{b})$. The ionic liquid layer was washed with water $(3 \times 10 \mathrm{~mL})$ and kept for $2 \mathrm{~h}$ at $80^{\circ} \mathrm{C}$ under reduced pressure. This ionic liquid was used in recycling. 2.3a $I^{\prime}$-Benzothiazolo-5'-phenyl-2',4'-dihydro spiro [indole-3,3'-pyrazol]-2(1H)-one (4a): $\mathrm{IR}(\mathrm{KBr}): 3400$ ( $>\mathrm{NH}$ of indole), 3290 ( $\mathrm{NH}$ of pyrazole), 1680 $(>\mathrm{C}=\mathrm{O})$; ${ }^{1} \mathrm{H}-\mathrm{NMR}(\delta) \mathrm{ppm}$ : $6.25(1 \mathrm{H}, \mathrm{s},=\mathrm{CH}-$ of pyrazole), $7.73(1 \mathrm{H}, \mathrm{s},-\mathrm{NH}$ of pyrazole $), 6.87-8.25$ $(13 \mathrm{H}, \mathrm{m}, \mathrm{Ar}-\mathrm{H}), 9.81(1 \mathrm{H}, \mathrm{s},>\mathrm{NH}$ of indole $) ;{ }^{13} \mathrm{C}-\mathrm{NMR}$ (ठ) ppm: 110.4 (spiro carbon), 118.2-137.5 (aromatic carbons $), 128.6(=\mathrm{CH}-$ of pyrazole $), 144.7(\mathrm{C}=\mathrm{N})$, $191.2(>\mathrm{C}=\mathrm{O})$; $\mathrm{MS}(\mathrm{m} / \mathrm{z}): 396\left(\mathrm{M}^{+}\right)$.

2.3b 1'-Benzothiazolo-1-methyl-5'-phenyl-2',4'-dihydro spiro[indole-3,3'-pyrazol]-2(1H)-one $(4 b)$ : $\quad \mathrm{IR}(\mathrm{KBr})$ : 3310 (NH of pyrazole), $1690(>\mathrm{C}=\mathrm{O}) ;{ }^{1} \mathrm{H}-\mathrm{NMR}(\delta)$ ppm: $3.48\left(3 \mathrm{H}, \mathrm{s},-\mathrm{NCH}_{3}\right), 6.19(1 \mathrm{H}, \mathrm{s},=\mathrm{CH}-$ of pyrazole), 7.85 (1H, s, -NH of pyrazole), $6.69-8.21(13 \mathrm{H}$, $\mathrm{m}, \mathrm{Ar}-\mathrm{H}) ;{ }^{13} \mathrm{C}-\mathrm{NMR}(\delta)$ ppm: $33.2\left(-\mathrm{NCH}_{3}\right), 109.9$ (spiro carbon), 117.8-137.2 (aromatic carbons), 128.4 $(=\mathrm{CH}$ - of pyrazole $), 145.2(\mathrm{C}=\mathrm{N}), 189.2(>\mathrm{C}=\mathrm{O})$.

\subsection{Preparation of 3-benzothiazolyl-1-phenyl-9H- pyridazino[3,4-b]indole $5 \boldsymbol{a}$}

Equimolar amount of 1a $(0.01 \mathrm{~mol})$ and $2(0.01 \mathrm{~mol})$ were dissolved in absolute alcohol $(10 \mathrm{~mL})$ and diethylamine $(1 \mathrm{~mL})$ added as a catalyst and reaction mixture was refluxed for $4-5 \mathrm{~h}$. After the completion of the reaction as evidenced by TLC, the reaction mixture was cooled at room temperature and solvent was evapourated under reduce pressure and the residue was chromatographed. (Silica gel 200-300 mes; eluent $=$ Pet. ether:EtOAc, 9:1; Pet. ether:EtOAc, 7:3; Pet. ether:EtOAc, 5:5 to afford 3, 4 and $\mathbf{5}$, respectively).

2.4a 3-Benzothiazolyl-1-phenyl-9H-pyridazino[3,4b]indole (5a): IR (KBr): $1620(\mathrm{C}=\mathrm{N}) ;{ }^{1} \mathrm{H}-\mathrm{NMR}(\delta)$ ppm: 7.40-8.34 (14H, m, Ar-H); ${ }^{13} \mathrm{C}-\mathrm{NMR}(\delta) \mathrm{ppm}$ : 115.2-138.4 (aromatic carbons); $\mathrm{MS}(\mathrm{m} / \mathrm{z}): 378\left(\mathrm{M}^{+}\right)$.

Analytical and physical data of the products were presented in table 1 .

Table 1. Analytical and physical data of the products.

\begin{tabular}{|c|c|c|c|c|c|c|}
\hline \multirow[b]{2}{*}{ Product } & \multirow[b]{2}{*}{$\mathrm{R}$} & \multirow[b]{2}{*}{ M.P. $\left({ }^{\circ} \mathrm{C}\right)$} & \multirow[b]{2}{*}{ Mol. formula } & \multicolumn{3}{|c|}{ Analysis (\%) Calcd./(found) } \\
\hline & & & & $\mathrm{C}$ & $\mathrm{H}$ & $\mathrm{N}$ \\
\hline 3a & $\mathrm{H}$ & 2 & C & $69.69 /(6)$ & $4.04 /(4$ & $14.14 /$ \\
\hline $\mathbf{3 b}$ & $\mathrm{CH}_{3}$ & $237-39$ & $\mathrm{C}_{24} \mathrm{H}_{18} \mathrm{~N}_{4} \mathrm{OS}$ & $70.24 /(70.31)$ & $4.39 /(4.42)$ & $13.66 /(13.57)$ \\
\hline $4 \mathbf{a}$ & $\mathrm{H}$ & $268-70$ & $\mathrm{C}_{23} \mathrm{H}_{16} \mathrm{~N}_{4} \mathrm{OS}$ & $69.69 /(69.76)$ & $4.04 /(4.15)$ & $14.14 /(14.03)$ \\
\hline $4 b$ & $\mathrm{CH}_{3}$ & 292-94 & $\mathrm{C}_{24} \mathrm{H}_{18} \mathrm{~N}_{4} \mathrm{OS}$ & $70.24 /(70.35)$ & $4.39 /(4.22)$ & $13.66 /(13.61)$ \\
\hline $5 \mathbf{a}$ & $\mathrm{H}$ & $223-25$ & $\mathrm{C}_{23} \mathrm{H}_{14} \mathrm{~N}_{4} \mathrm{~S}$ & $73.02 /(73.15)$ & $3.70 /(3.62)$ & $14.81 /(14.92)$ \\
\hline
\end{tabular}




\section{Results and discussion}

Theoretically, this reaction offers three different possibilities (scheme 1) viz., formation of hydrazone (3), spiro[indole-pyrazole] (4) as well as pyridazino derivatives (5) depending on the site of condensation. The products formed depended on the nature of solvent, medium and substitution on indolyl nitrogen. In simple 3-aroylmethylene-indol-2-one, the reaction gave only spiro[indole-3,3'-pyrazol]-2-one (4) in [bmim] $\mathrm{PF}_{6}$, an ionic liquid (an environmentally benign solvent), while it gave a mixture containing hydrazone (3) and spiro[indole-pyrazole] (4) in neutral and slightly acidic medium. In basic medium (ethanol with few drops of<smiles>O=C1Nc2ccccc2C1=CC(=O)c1ccccc1</smiles>

$\left[\mathrm{R}=\mathbf{H}, \mathrm{CH}_{3}\right]$

(1a-b)

$+$<smiles>NNc1nc2ccccc2s1</smiles>

(2)<smiles>O=C1Nc2ccccc2C12C=C(c1ccccc1)N(c1nc3ccccc3s1)N2</smiles><smiles>O=C1Nc2ccccc2/C1=C/C(=N/Nc1nc2ccccc2s1)c1ccccc1</smiles><smiles>c1ccc(-c2cc3c4ccccc4nc-3n(-c3nc4ccccc4s3)n2)cc1</smiles>

(5a)

Scheme 1. Synthesis of compounds (3a-b), $(\mathbf{4 a}-\mathbf{b})$ and $\mathbf{5} \mathbf{a}$.

Table 2. The reaction of 3-aroylmethylene-indol-2-ones with 2-hydrazinobenzothiazole.

\begin{tabular}{lllcccc}
\hline & & & & \multicolumn{3}{c}{ Yield $^{\mathrm{a}}(\%)$} \\
\cline { 5 - 7 } $\mathrm{R}$ & \multirow{2}{*}{ Solvent and medium } & Temp $\left({ }^{\circ} \mathrm{C}\right)$ & Time $(\mathrm{h})$ & $\mathbf{3}$ & $\mathbf{4}$ & $\mathbf{5}$ \\
\hline $\mathrm{H}$ & EtOH & Reflux & 5 & 30 & 55 & - \\
$\mathrm{H}$ & EtOH (Acidic) & Reflux & 5 & 36 & 52 & - \\
$\mathrm{H}$ & EtOH (Basic) & Reflux & 5 & 28 & 48 & 15 \\
$\mathrm{H}$ & $\mathrm{CH}_{3} \mathrm{COOH}$ & Reflux & 5 & 55 & 20 & 16 \\
$\mathrm{H}$ & {$[$ bmim]PF } & $80 \pm 2$ & 5 & - & 85 & - \\
$\mathrm{CH}_{3}$ & EtOH & Reflux & 5 & - & 63 & - \\
$\mathrm{CH}_{3}$ & EtOH $($ Acidic) & Reflux & 5 & 34 & 52 & - \\
$\mathrm{CH}_{3}$ & EtOH $(\mathrm{Basic})$ & Reflux & 5 & - & 72 & - \\
$\mathrm{CH}_{3}$ & $\mathrm{CH} \mathrm{COOH}_{3} \mathrm{COOH}$ & Reflux & 5 & 80 & 15 & - \\
$\mathrm{CH}_{3}$ & {$[$ bmim $] \mathrm{PF}_{6}$} & $80 \pm 2$ & 5 & - & 87 & - \\
\hline
\end{tabular}

asolated yield 
Table 3. Studies on the recyclability of $[\mathrm{bmim}] \mathrm{PF}_{6}$ for compound $\mathbf{4 a}{ }^{\mathrm{a}}$

\begin{tabular}{lccccc}
\hline Entry & Run & Time $(\mathrm{h})$ & Temperature $\left({ }^{\circ} \mathrm{C}\right)$ & Yield $^{\mathrm{b}}(\%)$ & $\begin{array}{c}\text { IL recover } \\
(\mathrm{w} / \mathrm{w} \%)\end{array}$ \\
\hline 1 & Fresh & 5 & $80 \pm 2$ & 85 & 97 \\
2 & 1 & 5 & $80 \pm 2$ & 82 & 95 \\
3 & 2 & 5 & $80 \pm 2$ & 80 & 92 \\
\hline
\end{tabular}

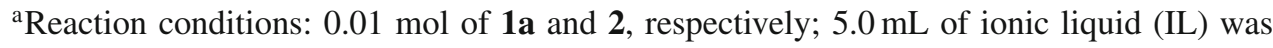
used for the first run.

${ }^{\mathrm{b}}$ Yields of product

diethyl amine) and pure acetic acid this affords a mixture of $\mathbf{3}, \mathbf{4}$ and $\mathbf{5}$. In the case of methyl substituted indolyl nitrogen, ionic liquid, neutral and basic medium afforded only the spiro product (4) while in acidic medium and pure acetic acid mixture of products viz., hydrazone (3) and spiro (4) were obtained. Our results indicate that when indolyl nitrogen is substituted then pyridazino derivative (5) was not formed at all. The reaction conditions and the yields of the products are summarized in table 2 .

The reactions were carried out in different reaction media and found that in acidic, basic and neutral medium, the reaction resulted in the formation of hydrazone (3), which under certain conditions, when $\mathrm{R}=\mathrm{H}$ can react with the enolic form eliminating water molecule to give the condensed product i.e., pyridazino derivative (5a). Alternatively, nucleophilic Michael addition of $\mathbf{2}$ to the $\mathbf{1 a - b}$ gives rise to spiro[indolepyrazole] $(\mathbf{4 a}-\mathbf{b})$.

Structure assignments to the products are based on spectral studies. The formation of hydrazone derivative 3a was confirmed by their IR spectrum which shows an absorption band at $3380-3200 \mathrm{~cm}^{-1}$ due to $>\mathrm{NH}$ and $1670 \mathrm{~cm}^{-1}$ due to the $>\mathrm{C}=\mathrm{O}$ of indole ring along with band at $1620 \mathrm{~cm}^{-1}$ due to $>\mathrm{C}=\mathrm{N}$. The ${ }^{1} \mathrm{H}-$ NMR spectrum has a peak due to $=\mathrm{CH}^{-}$at $\delta 6.18 \mathrm{ppm}$ along with the multiplet at $\delta 6.91-7.85 \mathrm{ppm}$ due to the aromatic protons. In ${ }^{13} \mathrm{C}$-NMR, signals appeared at $\delta$ $189.2,147.5$ and $121.3 \mathrm{ppm}$ due to the $>\mathrm{C}=\mathrm{O}$ of indole ring, $>\mathrm{C}=\mathrm{N}$ and $=\mathrm{CH}$ - carbons, respectively. Further, in the mass spectrum molecular ion peak appeared at $(\mathrm{m} / z) 396\left(\mathbf{M}^{+}\right)$.

In the IR spectrum of $\mathbf{4 a}$, absorption bands at 3400 and $3290 \mathrm{~cm}^{-1}$ due to $>\mathrm{NH}$ of indolinone and pyrazole, respectively and $1680 \mathrm{~cm}^{-1}$ due to $>\mathrm{C}=\mathrm{O}$ of indole are observed. In its ${ }^{1} \mathrm{H}-\mathrm{NMR}$ spectrum signals appeared at $\delta 6.25 \mathrm{ppm}$ due to pyrazolyl $=\mathrm{CH}^{-}, \delta \quad 9.81 \mathrm{ppm}$ due to $>\mathrm{NH}$ of indole ring and $\delta \quad 6.87-8.25 \mathrm{ppm}$ due to aromatic protons. ${ }^{13} \mathrm{C}$-NMR spectrum exhibited peaks at $\delta 191.2,128.6$ and $110.4 \mathrm{ppm}$ due to $>\mathrm{C}=\mathrm{O}$ (indole ring), $=\mathrm{CH}^{-}$(pyrazolyl ring) and spiro carbon, respectively. The structure was further, confirmed by mass spectrum, where molecular ion peak appeared at $m / z 396\left(\mathbf{M}^{+}\right)$corresponded to the molecular mass.

The chemical structure of pyridazino derivative (5a) was proven by their spectral characteristic, marked by disappearance of absorption bands due to $>\mathrm{NH}$ and carbonyl groups in the IR spectrum and appearance of $=\mathrm{CH}^{-}$peak in the aromatic region at $\delta 7.40-8.34 \mathrm{ppm}$ in its ${ }^{1} \mathrm{H}-\mathrm{NMR}$ spectrum. The structure was further confirmed by mass spectrum, where molecular ion peak $\left(\mathrm{M}^{+}\right.$at $m / z$ 378) corresponds to the molecular mass.

The reactivity of the recycled ionic liquid in the formation of $\mathbf{4 a}$ was studied. The yields of the product in two cycles are presented in table 3 , which indicates that the yield of $\mathbf{4 a}$ decreases in various cycles however the ionic liquid can be re-used with significant success.

\section{Conclusions}

In summary, investigation of the reactions between 3-aroylmethylene-indol-2-ones and 2hydrazinobenzothiazole was carried out in different media and solvents and found that ionic liquid, [bmim] $\mathrm{PF}_{6}$ was a good solvent to achieve spiro[indole-pyrazole] in excellent yield.

\section{Acknowledgements}

Financial assistance from the University Grants Commission (UGC), New Delhi to KS as Research Awardee, and for the Council of Scientific and Industrial Research (CSIR) to DK as SRF, is gratefully acknowledged.

\section{References}

1. Siddiqui N, Rana A, Khan S A, Ahsan W, Alam M S and Ahmed S 2008 Biomed. Pharmacol. J. 1(2) 297

2. Bondock S, Fadaly W and Metwally M A 2010 Eur. $J$. Med. Chem. 45(9) 3692

3. Saeed S, Rashid N, Jones P G, Ali M and Hussain R 2010 Eur. J. Med. Chem. 45(4) 1323 
4. Ramesh B and Bhalgat C M 2011 Eur. J. Med. Chem. 46(5) 1882

5. Siddiqui Z N, Musthafa T N M, Ahmad A and Khan A U 2011 Bioorg. Med. Chem. Lett. 212860

6. Nayak J, Girish K S, Babu M and Kalluraya B 2009 Indian J. Heterocycl. Chem. 19(2) 105

7. Da-Silva J F M, Garden S J and Pinto A C $2001 \mathrm{~J}$. Braz. Chem. Soc. 12273

8. Shmidt M S, Reverdito A M, Kremenchuzky L, Perillo I A and Blanco M M 2008 Molecules 13831
9. Joshi K C, Jain R, Dandia A and Sharma V 1986 J. Heterocycl. Chem. 23(1) 97

10. Joshi K C, Jain R and Garg S 1984 Pharmazie 4021

11. Joshi K C, Jain R and Sharma K 1990 Heterocycles 31(3) 473

12. Sharma K, Jain R and Joshi K C 1992 Indian J. Heterocycl. Chem. 1189

13. Lindwall H G and Maclennan J S 1932 J. Am. Chem. Soc. $\mathbf{5 4} 4739$

14. Sharma V and Sharma K V 2009 E-J. Chem. 6(2) 348 